\title{
Life Cycle Cost Analysis and Optimization of Modular Substation
}

\author{
Li Jun ${ }^{1}$, Zhang Fan ${ }^{1}$, Li Yinyuan ${ }^{1}$, Zhang Beibei ${ }^{2}$ \\ ${ }^{1}$ State Grid Anhui Electric Power Co., Ltd. Construction Company, Hefei, Anhui, 230071, P.R. China; \\ ${ }^{2}$ Anhui Jianzhu University, BIM Engineering Center of Anhui Province, Hefei, Anhui, 230601, P.R. China;
}

\begin{abstract}
Due to the lack of high standardization and specialization, the production scale of modular substation is difficult to meet the established requirements. Compared with traditional substation construction, there are still practical problems such as high production costs. Therefore, it is still difficult to promote modular substation. Considering the life cycle of modular substation project, Cost Breakdown Structure (CBS) and Engineering Breakdown Structure (EBS) of the modular substation were defined through literature reading and data analysis. Then use the life cycle cost mapping model to further determine the mapping relationship between CBS and EBS. Finally, the connotation and goal of the life cycle cost optimization of modular substation were proposed, which can effectively promote the cost management of modular substation projects and optimization.
\end{abstract}

\section{Introduction}

With the rapid development of China's economy and the improvement of people's living standards, the demand for power grid construction is also increasing rapidly. However, traditional substation construction projects still face many problems, such as the difficulty of land acquisition, long project cycle, large maintenance and repair work, and the complicated substation facilities that cannot be well integrated into the surrounding environment of the city.

Therefore, in order to improve the quality and efficiency of substation construction projects, substation construction is gradually developing towards modularization. At the same time, the analysis and optimization of modular substation project costs have increasingly become the focus of research. However, in the current construction process of modular substation projects, only the cost of the construction phase is the focus, which is the main reason for the high cost of modular substation projects. If it is possible to unify the various stages of the modular substation project, optimize the project cost for the life cycle, and identify the cost components of each phase of the modular substation project life cycle, and then use the appropriate method for each phase. The cost is optimized and controlled to effectively reduce the cost of modular substation projects.

\section{Structural decomposition of modular substation engineering system}

\subsection{Overview of modular substation}

A modular substation, also known as a combined substation, treats the substation as a whole and then divides it into different functional units according to the equipment category. In the design and construction stage, different functional units according to the division can be independently constructed in the factory building and then assembled in a modular manner.

In terms of design, build, construction and operation, modular substations are more adaptable than traditional substation construction ${ }^{[1]}$. Their characteristics and advantages are mainly reflected in the following aspects.

(1)Small floor space

The modular substation adopts a box prefabrication tank to build a workstation for electrical equipment, and the floor space is small, and each functional module is separately formed into a cabin, which improves the quality of equipment operation. At the same time, since the modular substation has almost no permanent buildings, it has sufficient flexibility and applicability to be more flexible to install and deploy, and can effectively cope with various construction environments.

(2)Short construction period

Since the modular substation project construction adopts the block-building construction method, the different modules of the modular substation can be designed at the same time. The prefabricated equipment is factory-prefabricated and transported to the site to realize "plug and play" and overall integration. Commissioning, as a result, the wiring and commissioning work of the modular substation is reduced accordingly, the construction efficiency is significantly improved, and the construction period is effectively shortened.

(3)Less on-site engineering

The modular substation is mainly based on factory prefabricated equipment. The primary and secondary equipment are integrated and installed in the factory. Each module can be pluged and played. Only a simple 
prefabricated foundation is needed on site. The amount of civil works is almost no, so there is almost no engineering work. The amount of engineering installed on the site of modular substation construction has been greatly reduced.

(4)Low construction cost

For modular substation projects, different modules can be designed simultaneously, effectively reducing labour costs. Moreover, each prefabricated module can be assembled and debugged as a whole, so the equipment installation workload is also greatly reduced.

\subsection{Engineering Breakdown Structure (EBS)}

(1) Engineering Breakdown Structure - the meaning of EBS

Engineering Breakdown Structure refers to the decomposition of the engineering system into a certain degree of engineering subsystem according to function, technology or professional, and then forms a tree structure based on the analysis of engineering system function ${ }^{[2]}$.

Engineering Breakdown Structure (EBS) is a scientific and effective method in project management, which is conducive to the life cycle management of engineering projects, which can significantly improve the level and performance of project management.

(2) The role of Engineering Breakdown Structure (EBS)

Engineering Breakdown Structure (EBS) is considered from the perspective of the life cycle of the project, and realizes the integrated management of each stage of the project. Engineering Breakdown Structure (EBS) plays an important role in project design, project planning, life cycle cost management, information management and organization management.

\subsection{Construction of Engineering Breakdown Structure of modular substation project}

In the modular substation project, firstly, according to the engineering technology system of the project, the engineering system decomposition structure (EBS) is the main goal, and the subsystems (professional elements) are obtained according to certain methods and rules, and then decomposed into tree structure from top to bottom. As shown in Figure 1, the modular substation Engineering Breakdown Structure (EBS) is first divided into three main system structures: system, electrical and civil engineering, and then the three main system structures are decomposed to obtain corresponding subsystems, for example By redecomposing the structure of the electrical system, the subsystems such as the power distribution device and the station substation system can be obtained, and then the subsystem can be decomposed again, such as redecomposing the station substation system, Get professional elements such as station transformer equipment foundation, prefabrication cabin, and station area lighting.

Engineering Breakdown Structure(EBS) Of the modular substation

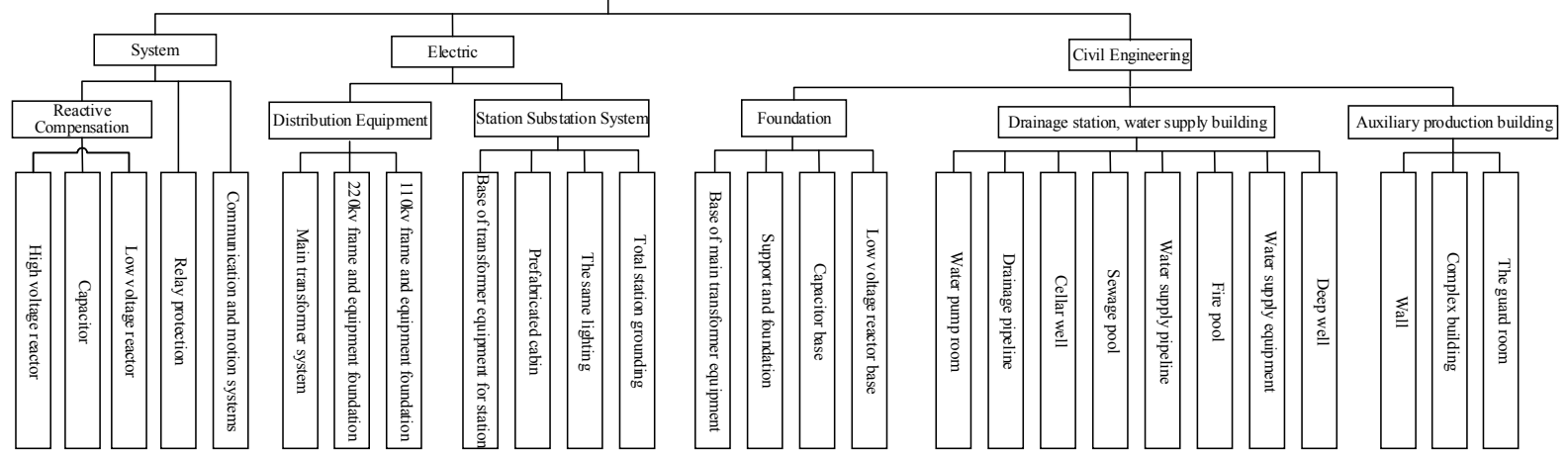

Figure1. Modular substation project engineering structure breakdown

\section{Modular substation project life cycle cost}

\subsection{Analysis of modular substation project cost}

Compared to the cost of traditional cast-in-place structures, the cost of modular substations has a more complex structure. Among other costs, the cost of the design period, the material cost during the production of the component, the labour cost, the cost during transportation, and the labour and material mechanical costs during installation and construction are also parts of the modular life cycle cost structure of the substation.

(1) Analysis of the current situation of design stage cost

The cost of the design phase is mainly due to the cost of the designer. At present, the main reason for the high design cost of modular substations is the large design content of prefabricated components, and the design procedure is cumbersome and deep ${ }^{[3]}$. The degree of standardization of prefabricated components, prefabrication completion rate, and assembly completion rate all have a significant impact on project costs.

(2)Analysis of the current situation of production stage cost

In the production stage, compared with cast-in-place modes, modular component production condition is good, can use mechanical assembly line and the template model of high levels of production to achieve a higher quality of concrete curing, avoid the traditional cast-in-situ mode caused by the construction site condition and adverse factors such as climate of waste material quality defects and problems such as rising costs, thus saving the cost of 
manpower and time cost, effectively reduce the production cost.

(3)Analysis of the current situation of transportation phase cost

In the transportation phase, the most critical is the transportation distance and route, because the vehicle's line will seriously affect the speed, cost and quality of component transportation. If the transportation route cannot be effectively selected, for example, the selection of the easy-blocking road section and the winding of the road line will lead to an increase in time and labour costs, and the transportation cost will also increase.

(4)Analysis of the current situation of production stage cost

In the installation phase, because the technical requirements of the modular substation are relatively high, it is necessary to train the construction personnel for a certain period of time in the early stage, which will lead to an increase in labour costs. At present, the main reason for the high design cost of modular substations is the large design content of prefabricated components have been installed on site, resulting in corresponding site management costs.

As the main direction of the future development of the construction industry, modular substations still have great market advantages. We must consider the life cycle of the project, optimize the project cost of the implementation of the modular substation project, identify the components of the life cycle cost of the modular substation project in stages, and use certain methods to control it. Moreover, optimization can effectively reduce project costs and promote the development of modular substations.

\subsection{Life cycle cost connotation and composition of modular substation project}

The project life cycle is the whole process from the project decision-making stage to the project retirement, and its research goal is the entire life cycle of the project. Here, using the cost-benefit analysis method of the project, the project life cycle cost management of the modular substation construction project from the perspective of the project life cycle can finally achieve the goal of LCC minimization ${ }^{[4]}$.

For modular substation projects, from a life cycle perspective, life cycle costs include:

$$
\begin{aligned}
& \mathrm{LCC}=\mathrm{C} 1+\mathrm{C} 2 \\
& \mathrm{C} 1=\mathrm{CI}+\mathrm{CJ}+\mathrm{CL}+\mathrm{CV} \\
& \mathrm{C} 2=\mathrm{CO}+\mathrm{CM}+\mathrm{CF}+\mathrm{CE}+\mathrm{CD}
\end{aligned}
$$

among:

C1: Construction Investment;

$\mathrm{C} 2$ : Operation and maintenance cost;

CI: Construction cost. It refers to the cost of carrying out civil works.

CJ: Reserve fee. It is the unpredictable cost during the preliminary design phase and the budgetary estimate.

CL: Equipment purchase fee. It is composed of the original equipment price and equipment transportation and miscellaneous fees, and refers to the equipment, tools and appliances that have been purchased for the construction project and have reached the fixed asset standard.

$\mathrm{CV}$ : Engineering overhead. The indirect costs in construction investment include land use fees, project management fees, design fees, supervision fees, and insurance fees related to project construction.

CO: Operating expenses. It refers to the cost of the resources consumed by the modular substation project during the operation process to complete the planned benefits.

CM: Maintenance and repair costs. It refers to the maintenance and repair costs necessary to ensure the normal operation of fixed assets such as substation equipment during the operation phase of the project.

CF: Failure power outage fee. It is resulted in power failure which caused by problems in the working equipment during the operation of the project.

$\mathrm{CE}$ : Expansion cost. It is the cost of the project's substation equipment that needs to be expanded according to the changes in conditions.

CD: Scarp value. It refers to the problem of insufficient production capacity of fixed assets such as existing substation equipment, thereby scrapping the inflow of funds from existing assets.

\subsection{Modular substation project cost structure decomposition}

The life cycle cost decomposition structure of the modular substation project is the premise of constructing the cost structure system and the basis for calculating and managing the life cycle cost of the project. In order to obtain accurate and perfect optimization and control of project costs, it is necessary to divide the cost components of each stage of the modular substation project from different aspects and angles, and to form a complete and rigorous system.

EBS in modular substation projects is an indispensable prerequisite for life-cycle cost management. The specific process is shown in Figure 2. From the perspective of project investment, the cost structure of the modular substation project can be divided. From the perspective of construction investment, it can be divided into construction project cost, construction installation cost, equipment purchase cost, reserve fee and overhead fee. It can also be divided into operating costs, inspection and maintenance costs, fault blackout costs, expansion costs and residual values from the perspective of operation and maintenance. 


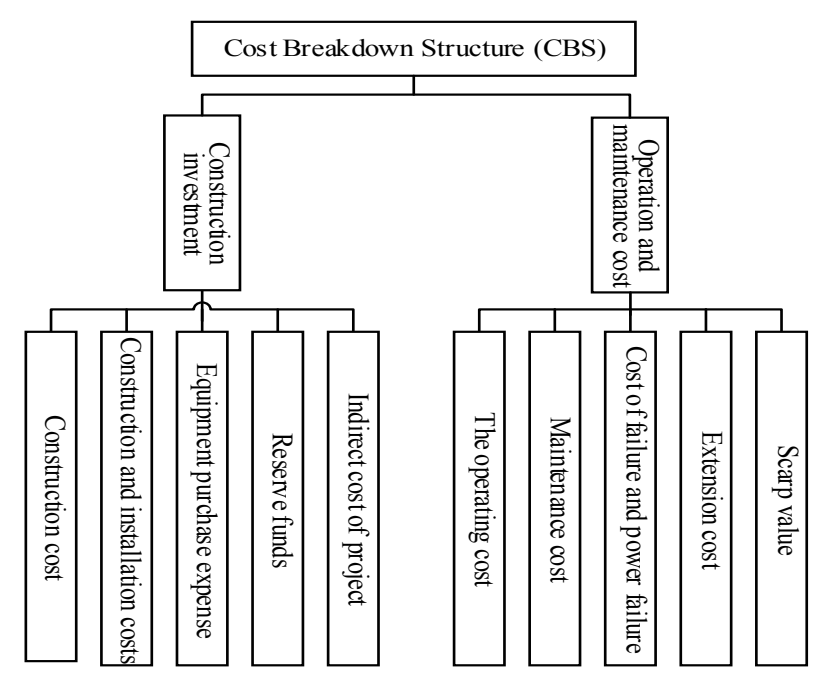

Figure2. CBS of modular substation
The mapping mechanism between a cost control unit and one or more unit tasks can be obtained by establishing a contrast reaction relationship between EBS and CBS ${ }^{[5]}$. According to the corresponding relationship mechanism, the life cycle cost mapping model of modular substation project was established as shown in Figure 3.

Through the project cost structure system, the project cost information can be summarized between various levels of organized, and it also control effectively at all levels and various stage between the factors of unit. In order to help managers acquire different levels and different stages of a family of cost, here it is concluded that in the engineering system structure at all levels through the analysis and summary, each stage management unit cost elements, and the expense of the same nature at different stages can also be combined with different degrees of engineering system decomposition structure, enabling it to adapt to all kinds of complicated situations.

\section{The life cycle cost mapping model of the project of modular substation}

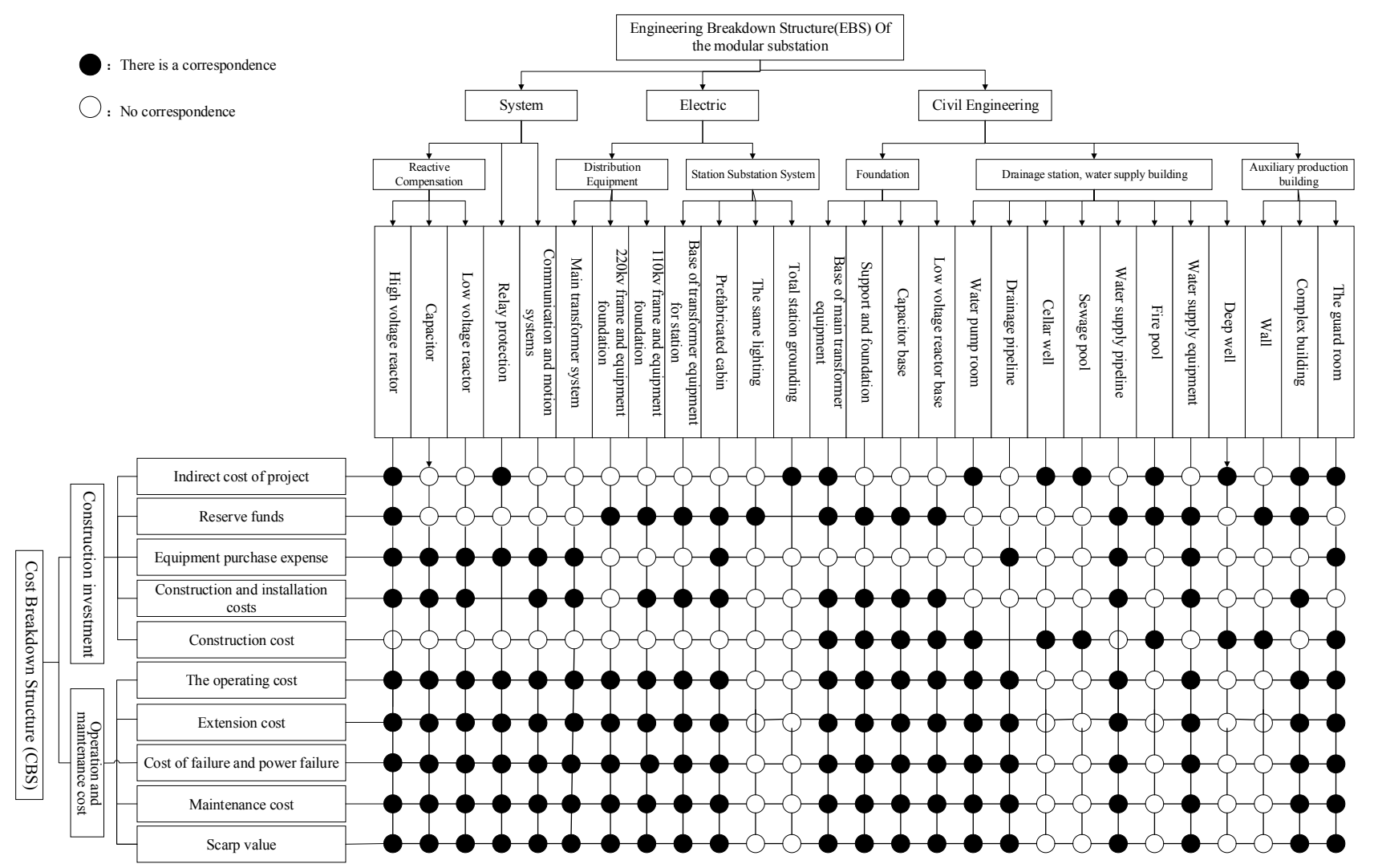

Figure3. Modular substation project life cycle cost mapping model

\section{The life cycle cost optimization of modular substation}

Life cycle cost optimization refers to the entire life cycle of each phase, and this is the minimum precondition to ensure that various stages of the life cycle of the whole process cost. The purpose of life cycle cost optimization is to achieve the lowest cost on the premise of guarantee the engineering quality and safety ${ }^{[6]}$. As shown in Table
1 , the cost optimization method in life cycle were proposed.

Table1. Cost optimization scheme for each stage of the whole life cycle of modular substation

\begin{tabular}{|c|c|}
\hline $\begin{array}{c}\text { Project } \\
\text { stage }\end{array}$ & Optimization plan \\
\hline
\end{tabular}






\section{Conclusion}

At present, due to the lack of high standardization, specialization and production scale, modular substation construction is difficult to meet the requirements. From the perspective of life cycle cost optimization, this paper analyzes the life cycle cost of the project. The mapping mechanism between CBS and EBS is established by using life cycle cost mapping model, and the connotation and optimization scheme of life cycle cost optimization of modular substation are put forward, which provides an effective way for the promotion and cost optimization of modular substation construction projects.

\section{References}

1. Lu Chen. Research on progress management of modular substation construction based on key chain method[D]. Dalian University of Technology.2018

2. Ye Jian, Sun Fupeng. Application feasibility analysis of modular substation in Southern Power Grid[J]. Guang xi Power Industry.2018:52-55

3. Dong Deyong. Research on the modular construction of intelligent substation in Liaoning Province[D]. North China Electric Power University.2018

4. Sun Huijun, Zhou Fengjiao. On the optimization design of life cycle cost of substation. Guangdong Science\&Technology.2014:25-26

5. Rashidul Islam, Tasnia Hassan Nazifa, Sarajul Fikri Mohamed. Factors Influencing Facilities Management Cost Performance in Building Projects[J]. Journal of Performance of Constructed Facilities,2019,33(3):56-71

6. Haiyan, Jin,Liyin Shen, Zheng Wang. Mapping the Influence of Project Management on Project Cost[J]. KSCE Journal of Civil Engineering,2018,22(9):72-83 